\title{
PROGRAMAS DE HABITAÇÃO SOCIAL NO BRASIL
}

\author{
Thaís Almeida Siqueira \\ Graduanda em Arquitetura e Urbanismo/ISECENSA/RJ \\ thais_asiqueira@hotmail.com \\ Ronaldo de Sousa Araújo \\ Doutor em Gestão e Valoração Urbana/UPC/Barcelona/Espanha \\ r.saraujo@hotmail.com
}

\section{RESUMO}

O presente estudo tem por motivo analisar os Programas de Habitação Social no Brasil, que surgiram com os processos de urbanização das cidades, tendo um consequente crescimento populacional. Desde de 1928, vem sendo discutido por vários arquitetos, urbanistas e o poder público, maneiras de solucionar os grandes problemas que a falta de habitação acarreta para população. A necessidade de construção de habitações de qualidade é extremamente importante, porém não é isso que vem sendo feito pelo poder público e privado, pois para eles quantidade é melhor que qualidade. E o objetivo dessa pesquisa é discutir sobre a realidade desses programas de habitação, sobre a escolha de quantidade ou de qualidade ou os ambos. E com o decorrer do trabalho é nítido a precária evolução que os programas tiveram em mais de meio século.

Palavras Chaves: Habitação Social, Quantidade, Qualidade.

\begin{abstract}
The present study is to analyze the reason of Social Housing Programs in Brazil, which emerged with the processes of urbanization of cities, with a consequent population growth. Since 1928, has been discussed by several architects, planners and the public sector, how to solve big problems that homelessness leads to population. The need for housing construction quality is extremely important, but this is not being done by the public and private power, because for them quality is better than quantity. And the goal of this research is to discuss the reality of these housing programs on the choice of quantity or quality or both. And in the course of work is crisp precarious developments that programs have had in over half a century.
\end{abstract}

Keywords: Social housing, quantity, quality.

\section{INTRODUÇÃO}

Com o processo de urbanização das cidades e consequentemente crescimento populacional, foi necessário a construção de habitações em grandes quantidades. Em muitos países os processos de urbanização e industrialização se misturam. E uma das soluções fornecidas pelo poder público, e também por empreendedores privados, foi a construção de conjuntos habitacionais. Suprindo a demanda no Brasil e em outros países como na Europa.

Esse tema vem sendo discutido desde 1928, onde os arquitetos e urbanistas juntos com o poder público, pretendem achar soluções viáveis e econômicas que favoreça tanto a população como os municípios.

Com o aumento acelerado da população do planeta, em particular das camadas de escassos recursos, os conflitos políticos, étnicos, religiosos e as progressivas catástrofes naturais, produziram uma significativa população sem moradia, ou assentada em urbanizações precárias, provisórias e marginais. 
O projeto da habitação social é, sem dúvida, um dos mais difíceis na medida em que qualquer gesto pressupõe um controle muito grande de custos, uma racionalização extrema que infelizmente traduz-se numa pobreza de propostas muito grave. Em diversos momentos, a habitação para pobres foi entendida de fato como habitação pobre, de ideias pobres e de baixa qualidade.

Mas o grande dilema é, fazer poucas habitações, porém de qualidade, ou fazer muitas habitações, com pouca qualidade? Este é um dos objetivos dessa pesquisa, debater sobre assuntos relacionados a habitação, população e município. Que foram pesquisados em livros, internet, jornais e revistas. E justificando a necessidade do poder público em analisar os problemas da população, e conseguir resolvê-los da melhor forma possível para todos. Concluindo que, os Programas de Habitação Popular no Brasil têm muito o que evoluir, para que a construção de grandes conjuntos habitacionais resolva a maioria dos problemas de habitação deste país.

\section{DISCUSSÃO}

\subsection{Origem dos Projetos de Habitação no país}

Até a primeira metade do século $\mathrm{XX}$, não se imaginava a existência de uma família sem a casa, que representava a indispensável proteção da vida privada contra a adversidade da natureza e os perigos do mundo exterior. No entanto, com as transformações sociais e econômicas ocorridas depois da Segunda Guerra Mundial, e o surgimento e desenvolvimento dos países do Terceiro Mundo, criaram uma separação entre casa e indivíduo.

Para Aymonino (1973), as discussões sobre as moradias foram temas de debates nos Congressos Internacionais de Arquitetura Moderna - CIAMs, a partir de 1928. Estes foram criados com o intuito de reunir arquitetos preocupados com qualidade física-espacial das cidades em função da consolidação dos processos industriais, e como estes poderiam ocorrer em relação à construção de edificações. As edificações deveriam atender as necessidades da sociedade atual.

O desafio de abrigar a grande massa de população que chegava às cidades, os modernos pensam em pequenas unidades com serviços coletivos, construção racionalizada e baixos custos. É o resgate da habitação social como objeto de reflexão, propondo-se uma nova arquitetura para uma nova cidade.

\subsection{Modelo de Conjunto Habitacional no Brasil}

De acordo com Benetti (2012), em 1946, o Conjunto do Pedregulho começou a ser construída, obra do Arquiteto Affonso Eduardo Reidy e Carmen Portinho, este conjunto habitacional é uma obra da arquitetura moderna, onde coloca o Brasil na vanguarda dos movimentos internacionais. O projeto é totalmente inédito para a época, aliando questões urbanas a uma conformação arquitetônica. $\mathrm{O}$ projeto consiste em: lavanderia coletiva, escola, clube com piscina e posto de saúde, adjudica os apartamentos não pela renda familiar, mas pelo tamanho da família, ou seja, uma verdadeira inovação. Todos os princípios da arquitetura moderna estão inseridos, mas de maneira particular, pilotis no meio da edificação, estrutura independente, paredes não estruturais, e uma forma que segue a forma e não a função de maneira simplista.

Porém, depois com todo estudo de todos os tipos de habitações e conjuntos habitacionais, o Pedregulho não era uma solução viável para a grande maioria da população, mas o que temos é um modelo, um objeto que até hoje serve como referência de qualidade. Este será sempre um dilema àqueles que fazem habitação social, em face da enorme carência: fazer mais habitações, ainda que de menor qualidade, ou fazer menos habitações de boa qualidade? (BENETTI, 2012)

Segundo Cavalcanti (2002), se o Pedregulho prima pela qualidade de seus espaços, pela riqueza de suas formas, pela correta inserção urbana, pelo programa revolucionário, o que vem depois é uma coleção de insucessos, habitações guiadas somente pelo princípio do menor custo e grande escala. A associação perversa entre a racionalização da construção, menor custo e pré-fabricação pesada, determina a procura por lotes de grandes dimensões naturalmente afastados da malha urbana. A outra alternativa habitacional são as casinhas suburbanas financiadas pela Aliança para o Progresso 
e construídas no marco da maior remoção de populações faveladas da nossa história. Refletem a discussão ideológica que associa a pequena propriedade urbana à manutenção da família e, consequentemente, da tradição e da propriedade.

\subsection{Criação do BNH}

As casas começaram a ser localizadas muito distantes da malha urbana consolidada, além de aumentar o custo das cidades, comprometeram gravemente a possibilidade de melhoria social das famílias, à medida em que são lugares carentes de possibilidades de trabalho, emprego, cultura, lazer e educação. As localizações dos conjuntos e as casas suburbanas acabam provocando certo confinamento das populações em função do alto custo dos transportes.

A partir de 1964, o BNH construiu significativo número de conjuntos habitacionais populares nas periferias das cidades brasileiras, para onde milhares de famílias foram levadas para morar. Os problemas técnicos e sociais relacionados a esse tipo de empreendimento são insistentemente apontados por aqueles que atuam na área de habitação e planejamento urbano. Entre as críticas, destacam-se aquelas relacionadas à precária inserção urbana dos conjuntos, à monotonia e má qualidade dos projetos urbanísticos e arquitetônicos, à má qualidade da construção e aos riscos de formação de guetos, socialmente excluídos do restante das cidades.

De acordo com Freitas (2002), o BNH, Banco Nacional da Habitação, marcou uma nova fase da política habitacional federal. Criado pelo regime militar, o BNH teve como objetivo central dar sustentabilidade ao sistema de crédito habitacional, através da instituição de uma fonte de recursos permanente.

Quando o BNH buscou reduzir o custo da moradia para tentar atender a uma população que vinha se empobrecendo, ao invés de alterar o processo de gestão e produção que encarecia o produto final, apoiando iniciativas que a população já vinha promovendo, optou por rebaixar a qualidade da construção e tamanho da unidade, financiando moradias cada vez menores, mais precárias e distantes (...). (BONDUKI, 1998)

Para Arretche (1990), auxiliar o lado empresarial do BNH, foi criado o Sistema Financeiro Habitacional (SFH) com o objetivo de facilitar o acesso da população de baixa renda à casa própria e novas, financiando-as com menos de 180 dias de 'habite-se', gerando um boom no setor imobiliário, ao mesmo tempo em que se desconsideravam imóveis com condições de habitabilidade e que poderiam ser disponibilizados por menor custo. Outro imperativo que favorecia a construção de novas moradias era, como já mencionamos, o de dinamizar a economia através da construção civil.

A expansão das atividades do BNH não se deu, todavia, como mero resultado do cumprimento de dispositivo legal. A experiência dos primeiros anos tinha mostrado que não bastava apenas construir casas: era preciso dotá-las de infraestrutura adequada. Os conjuntos habitacionais eram alvo de críticas precisamente por lhes faltarem esses requisitos (ANDRADE \& AZEVEDO, 1982).

Segundo Medeiros (2011), em novembro de 1986, no meio do segundo Plano Cruzado, o governo Sarney decidiu fechar o BNH (Decreto Lei 2291/1986), o chefe do sistema, que empregava cerca de 10.000 pessoas. Os funcionários foram absorvidas por outros organismos públicos, especialmente a Caixa Econômica Federal, ou CEF, também chamada de CAIXA (outro banco público), que também assumiu muitas das funções do BNH. A política habitacional brasileira fica com um vazio. As atribuições do BNH foram pulverizadas para diversos órgãos: $\mathrm{CEF}$, secretarias e ministérios, responsáveis pela elaboração das políticas.

Para Palhares (2001), com o fim do BNH, surgiram outros projetos de habitação social, e um deles foi o Projeto Moradia, criado pelo poder Executivo Federal, ainda que já se tenha extinguido, estabeleceu princípios de descentralização que merecem ser destacados. O projeto pressupunha a mobilização de toda a sociedade em torno de uma proposta, na qual o Estado tinha papel fundamental, 
mas não exclusivo, e a sociedade civil era determinante em sua concretização. Nenhum dos agentes governo, setor privado, legislativo, judiciário, movimentos sociais, organizações não governamentais, universidades, agentes técnicos e entidades de classe - ficava de fora do processo que exigia participação ampla de toda a sociedade brasileira. O trabalho também apontava para contextualização dos modelos a serem implantados, muito cara aos princípios de descentralização, em que as novas propostas, em contraposição aos modelos prontos, deveriam considerar a diversidade material e cultural na qual seriam inseridas.

\subsection{Novos Programas de Habitação}

De acordo com Palhares (2001), a articulação das propostas priorizava a questão da moradia e instituía um sistema de gestão e controle social, que fosse responsável pela implementação das ações necessárias, e se daria no âmbito da administração pública nacional, estadual, ou municipal. Os diversos agentes descentralizados atuariam com proximidade dos problemas a serem enfrentados. $\mathrm{Na}$ medida em que conhecessem as realidades regionais e locais, poderiam buscar soluções mais baratas e coerentes com materiais e mão de obra disponível. Reduziriam custos, aumentariam a participação popular e, consequentemente, confeririam maior qualidade às habitações produzidas. $O$ projeto visava atender como população alvo as famílias com renda de até três salários mínimos, evitando os erros passados pelas distorções no atendimento em relação ao BNH. O projeto ainda propunha a participação de agentes de retaguarda, como universidades, centros de pesquisa e de qualificação profissional, constituindo um quadro técnico de profissionais habilitados. Seriam também desenvolvidas inovações tecnológicas, que estabeleceriam novas possibilidades de uso de materiais, com maior durabilidade e custos mais reduzidos, conferindo aos empreendimentos maiores possibilidades de sucesso na superação das dificuldades econômicas.

Na condição de país em desenvolvimento, o Brasil presencia uma evolução em seu espaço. No momento atual, a modernização tecnológica está difundindo novas ideias para os construtores e o poder público, promovendo utilização de novos materiais e recursos sem qualidade, prejudicando a população que ali irá morar. Segundo a Lei 11.977, o programa "Minha Casa Minha Vida" tem como finalidade criar incentivos ao governo local para a construção de novas unidades habitacionais para população que vive em risco, com renda menor que dez salários mínimos. (BRASIL, 2009)

Esses programas do governo são necessidade atuais da sociedade, mas o descaso com a população é tão grande, que a falta de contribuição está transformando a cidade em um caos. Precisamos de incentivos sérios, de empresas e governos, para que exista uma mudança na vida dessas pessoas. A formação de guetos e favelas é resultado de todos os problemas que a sociedade está passando.

O PMCMV é apontado como "uma das principais ações do governo em reação à crise econômica internacional - ao estimular a criação de empregos e de investimentos no setor da construção - e também como uma política social em grande escala" (ARANTES, 2009). Uma das principais razões do governo por esse programa é a real possibilidade da redução do déficit habitacional brasileiro, porém eles não percebem que apenas uma tipologia de construção para o país inteiro não irá ter resultados agradáveis.

\subsection{Diferentes culturas e falta de escolha}

O Brasil é um país muito extenso, com culturas espalhadas por todo o território, e totalmente diferentes umas das outras. Cada estado tem seus costumes, cada cidade tem seus hábitos, que diferem muito de Norte a Sul. E um mesmo programa para todo um país, com diferentes comportamentos e etnias, nunca será eficaz e sempre ocorrerão os mesmo erros. O governo resolve singularizar a população, e fazer um tipo de habitação que "ache" que resolva para todos os moradores. Mas isso é mero engano, porque nenhuma pessoa que receber uma casa sem ter dado nenhum palpite nela, se sentirá "em casa".

A uniformização das moradias pelo país acarreta em diversos problemas pelos municípios. O Brasil é um país com diversos tipos de culturas, e não tem como igualarmos o lar das pessoas. 
Precisamos de soluções viáveis, que ajudem a modificar os programas de habitação, para que as pessoas recebam as casas sem reclamações e que eles cuidem delas.

A maioria dos cidadãos de um país possui hábitos uniformes de viver e de morar; [...]. Todavia deve-se evitar o perigo de uma padronização demasiadamente rígida [...] e as casas devem ser projetadas de modo a levar em consideração as necessidades individuais, derivadas do tamanho da família e da profissão do chefe da família, assegurando sua flexibilidade. Deve-se, portanto, padronizar e produzir em série não a casa inteira, mas suas partes, de modo que formem, com suas combinações, vários tipos de casas (GROPIUS, 1924).

E a população que ali residirá não tem escolha, alternativa, ou outra opção de moradia, tendo que se adaptar a um local novo, com novos vizinhos e uma habitação nova e definitiva, onde a pessoa terá que onerar o orçamento doméstico em um período considerável, e custear quaisquer alterações ou adaptações que será feita na moradia. $O$ processo de construção deveria ter participação, escolha e tomada de decisões ao longo do tempo, o que iria facilitar muito a aprovação dos habitantes que ali residirão.

Do ponto de vista da população pobre, uma questão fundamental relativa à habitação nas condições atuais aqui se coloca: a casa própria seria de fato a forma mais adequada de provimento de moradia para este contingente populacional? Em um importante e pioneiro estudo sobre políticas habitacionais brasileiras, escrito em finais dos anos 70, Gabriel Bolaffi já observava que o aluguel, além de menos oneroso, seria mais adequado para grande parcela da população, sujeita a processos diversos de mobilidade (BOLAFFI, 1981).

A proposta do governo de apenas uma alternativa de moradia, em meio a tantas outras, retira o poder de escolha das pessoas e a decisão do melhor pra si. Todas as pessoas têm direito a liberdade, ao poder de expressão, e a falta ou o não saber disso implica em graves problemas para o governo, porém eles são taxativos e não permitem a alternativa para população.

\subsection{Zonas Especiais de Interesse Social mal localizadas}

O país esteve dividido em ricos e pobres, havendo uma dificuldade de planejamento. Onde um terreno no centro da cidade ou em uma área nobre será doado ou permitido pela população que ali reside, para ser transformado em Zonas Especiais de Interesse Social. Nenhuma pessoa, por qualquer renda que ela tiver, não vai querer que sua casa seja desvalorizada com a colocação de um condomínio habitacional social ao seu lado. Então, o governo de mãos atadas, resolve colocar esse condomínio habitacional na periferia, local de ruim acesso, que prejudica a cidade e a população que ali reside. E como está na lei todo local que for feito uma habitação social, terá que ter equipamentos comunitários por perto, para aquela população que ali residirá.

A primeira questão que se propõe como critério de projeto diz respeito à emergência de conjuntos de Habitação de Interesse Social inseridos na dinâmica da vida urbana. Ao se propor a inserção de Habitação de Interesse Social em áreas melhor localizadas com relação às áreas centrais, concentradoras da maior parte dos empregos formais da cidade, discute-se, consequentemente, a inserção da população de baixa-renda em áreas providas de equipamentos urbanos de saúde, educação, lazer e cultura. O que garante o acesso democrático ao espaço da cidade, a partir de uma ação do Estado, promove a mudança da mentalidade colonial e altera a prática de outros segmentos da sociedade. 
para que o Programa Minha Casa Minha Vida construa moradias adequadas e bem localizadas é essencial a participação ativa dos municípios mobilizando instrumentos em seus Planos Diretores que favoreçam a disponibilidade de bons terrenos para o programa, especialmente para famílias com renda de 0 a 6 salários mínimos" (ROLNIK, 2010).

De acordo com a arquiteta Ermínia Maricato, em entrevista ao programa Sem Fronteiras, alertou: precisamos nos armar de uma "vontade férrea", essencialmente, em duas frentes - (1) a aplicação do Estatuto da Cidade, no que se refere à função social da propriedade e à regularização fundiária e imobiliária; e (2) o aprendizado do setor privado, ainda retido por um produto de luxo, sobre a produção da habitação para pessoas de baixa renda. Não é simples evitar a pressão dos grandes proprietários de terras, do setor imobiliário e da indústria da construção civil não se sobreponham ao desejo do poder público obter terrenos bem localizados e construir adequadamente? Como impor a vontade férrea dos agentes públicos aos agentes privados? Como romper com a política habitacional que exclui os cidadãos de seus processos de decisão, transferindo a responsabilidade da moradia ao poder privado?

\subsection{Quantidade ou Qualidade na Habitação Social}

Para Albuquerque (2011), a moradia no Brasil tem se reduzido a um produto como outro qualquer e o morador a consumidor passivo, cujas opções resumem-se a escolhas limitadas dentro de um rol pré-concebido de opções determinadas por outrem. A Caixa Econômica Federal financiou 1 milhão de moradias em 2010, das quais 936,5 mil unidades tiveram intervenção direta da Caixa, com investimentos de $\mathrm{R} \$ 51,3$ bilhões. Foram beneficiadas 91 mil famílias com renda entre dois e três salários mínimos, bem abaixo da meta estabelecida de 400 mil moradias.

Conforme Figuerola (2009), sob o ponto de vista da Caixa Econômica Federal, representada na fala do pelo seu vice-presidente Jorge Hereda, o Programa Minha Casa Minha Vida "faz parte de uma política anticíclica que tem por objetivo aumentar os investimentos no setor da construção civil e garantir a geração de emprego e renda e, assim, mitigar os impactos da crise econômica mundial". Ingenuidade entender que tais argumentos possam significar o rompimento de uma política que historicamente vem reforçando a mercantilização da casa própria por meio do lucro que a indústria de construção civil recebe.

O Programa Minha Casa Minha Vida não será uma política anticíclica social, mas uma política imobiliária que terá efeitos de médio prazo sobre o mercado de trabalho (ARANTES, 2009).

Para Rolnik (2010), o governo federal, por meio do Ministério das Cidades, reconhece a produção de moradia social em zonas consolidadas e bem localizadas como necessária em contraponto ao planejamento historicamente construído por padrões de regulação urbanísticas elitistas e segregadores. Porém, apresenta diretrizes em seus programas habitacionais que nos fazem acreditar na continuidade desses padrões. Em tese, os recursos do PMCMV poderiam ser direcionados para a produção de moradias em terrenos bem localizados e dotados de infraestrutura. Na prática, o poder público alimenta o setor imobiliário na medida em que cabe às construtoras não só definir terreno e projeto (localização e tipologia) bem como aprovar legalmente o empreendimento.

$\mathrm{Na}$ outra ponta, a Caixa Econômica Federal garante a venda integral das unidades além de eliminar os riscos de inadimplência dos compradores. Imprimem-se aqui as regras das construtoras e incorporadoras nos programas habitacionais, ou seja, a inserção da casa como produto do mercado imobiliário, de modo a garantir maior rentabilidade do capital dessas empresas. Sendo assim, não será a boa localização, a existência de infraestrutura, a qualidade espacial dos projetos, as diretrizes para a coexistência social, fatores decisórios na produção habitacional quando regida pelas construtoras (MORADO NASCIMENTO E TOSTES, 2010). 


\subsection{Programas Sociais desatualizados}

Quase meio século depois, permanece na atual política habitacional a mesma lógica de funcionamento do BNH estruturada pelo aumento do consumo da moradia e pela garantia do trabalho das empreiteiras. A preocupação com a racionalização e a mecanização de processos em atendimento às premissas da produção em massa, fomentadas pelo desejado e necessário desenvolvimento da indústria da construção, impediu que o BNH incorporasse à promoção da autonomia dos usuários, a desburocratização dos financiamentos, a reabilitação dos centros urbanos, a provisão da moradia para a população de baixa renda e a geração de espaços públicos democraticamente acessíveis. Parece que a lição sobre a política habitacional do período BNH ainda há de ser aprendida.

O Programa Minha Casa Minha Vida precisa ser reavaliado o seu ponto de vista tanto quantitativo, quanto qualitativo. O programa está ultrapassado, ele não propõe mudanças e não incorpora avanços para o bem da população e a evolução da cidade. O morar é um processo que ultrapassa a construção, o espaço da edificação, e sim constituindo processos sócio espaciais mais amplos em nível local, nacional e mesmo mundial.

De acordo com Morado Nascimento e Tostes (2010), morar nas cidades brasileiras implica absorver com maior ou menor comprometimento os padrões de desigualdade e segregação característicos do nosso espaço e de nossa sociedade, cujas características afetam diretamente a situação dos indivíduos, suas possibilidades e perspectivas. $\mathrm{O}$ espaço não é ocupado ao acaso, e a transformação que define os padrões qualitativos e quantitativos desta ocupação é fundamental para o enfrentamento da questão habitacional brasileira. Desta maneira, habitação e urbanização se conformam mutuamente, refletindo e definindo condições mais amplas de nossa economia, de nossa sociedade e da inserção do país no sistema mundial.

O Programa Minha Casa Minha Vida não apresenta explicitamente possibilidades de transformação de muitos dos problemas de nossas cidades, reproduzindo a consideração isolada dos aspectos que condicionam a qualidade do habitat urbano. Ao reduzir o morar às unidades habitacionais, sem menção às questões que definem a localização e suas relações com o espaço e a vida mais ampla das cidades, o Estado brasileiro acaba por colaborar na reprodução de vários dos problemas de nossa urbanização, perdendo uma grande oportunidade de transformar os padrões perversos característicos dos espaços de nossas cidades (MORADO NASCIMENTO, BRAGA, 2009).

Conjuntos habitacionais construídos em locais distantes, ermos, oferecendo péssimas condições de vida a seus moradores, igualmente exigindo a implantação de serviços básicos, a um custo muitas vezes maior do que o desembolso necessário para a recuperação de moradias em áreas deterioradas, como as regiões centrais das capitais. A alegada falta de recursos para a questão da moradia e a correlata deterioração da qualidade de vida nas cidades para a população como um todo é apenas a outra face do desperdício e má aplicação do dinheiro público das Prefeituras, Estados e União, por falta de uma política habitacional e urbana no País. Obviamente, nenhuma das distorções é acidental. Elas refletem a predominância de interesses econômicos, desconsiderando-se os interesses de toda a população coletivamente e das famílias sem acesso à habitação, especificamente (PROJETO MORADIA, 2001, p.47).

Para Nascimento (2011), a efetividade do programa precisa ser avaliada não só do ponto de vista quantitativo, mas principalmente qualitativo. A análise dos pressupostos e das decorrências dos parâmetros utilizados tanto na definição dos espaços das habitações como dos espaços externos resultantes e de seus impactos na conformação das cidades, permite considerar que as contribuições do programa são muito pequenas quando não inexistentes. $O$ programa não propõe avanços, nem incorpora avanços já consolidados na abordagem dos espaços e no entendimento do que seja o direito à cidade. $\mathrm{O}$ morar é um processo definido por uma rede articulada e complexa de agentes, de relações e de interações que ultrapassam em muito o âmbito estrito do espaço da edificação, implicando em sua constituição processos sócio espaciais mais amplos em nível local, nacional e mesmo mundiais. Morar 
nas cidades brasileiras implica absorver com maior ou menor comprometimento os padrões de desigualdade e segregação característicos do nosso espaço e de nossa sociedade, cujas características afetam diretamente a situação dos indivíduos, suas possibilidades e perspectivas. O espaço não é ocupado ao acaso, e a transformação das dinâmicas que definem os padrões qualitativos e quantitativos desta ocupação é fundamental para o enfrentamento da questão habitacional brasileira, indissociada dos padrões gerais de nossa urbanização. Desta maneira, habitação e urbanização se conformam mutuamente, refletindo e definindo condições mais amplas de nossa economia, de nossa sociedade e da inserção do país no sistema mundial.

O PMCMV não apresenta explicitamente possibilidades de transformação de muitos dos problemas de nossas cidades, reproduzindo a consideração isolada dos aspectos que condicionam a qualidade do habitat urbano. Ao reduzir o morar às unidades habitacionais, sem menção às questões que definem a localização e suas relações com o espaço e a vida mais ampla das cidades, o Estado brasileiro acaba por colaborar na reprodução de vários dos problemas de nossa urbanização, perdendo uma grande oportunidade de transformar os padrões perversos característicos dos espaços de nossas cidades (TOSTES, 2011).

\section{CONCLUSÃO}

Este artigo explica alguns Programas de Habitação Social que foram realizados no Brasil, como o Pedregulho, o BNH e o Minha Casa Minha Vida. E a necessidade de construção dessas casas populares para a população carente. Porém é necessário o apoio do poder público e privado para que haja a produção de casas de qualidade e em grande quantidade.

Para a construção de moradias, o poder público desapropriou grandes lotes distantes do centro urbano. Acarretando em construções de má qualidades, em locais sem nenhuma estrutura como escola, creche, posto de saúde, posto policial entre outros, e principalmente sem meio de transporte, formando guetos socialmente excluídos do restante da cidade.

Além disso, o Brasil é um país muito extenso, com diversas culturas o que provoca problemas na padronização das construções dos Planos de Habitação Social. Onde as casas deveriam ser projetadas levando em consideração as necessidades individuais de cada família, como a quantidade de pessoas que ali residirá, e a profissão do chefe de família. Assim, padronizando não a casa inteira, e sim suas partes, de forma, que forme combinações de vários tipos de casas.

Os programas de habitações sociais precisam ser avaliado tanto quantitativamente como qualitativamente, e o governo precisa desenvolver propostas que facilitem e tornem viáveis a construções de habitações de boa qualidade, e diferenciadas sendo aplicadas de modo diferentes de Norte a Sul do país.

Conclui-se que os Programas de Habitação Popular no Brasil têm muito que melhorar em qualidade e diversidade de projetos, porque com a falta de uma política habitacional e urbana, está havendo um desperdício e má aplicação do dinheiro público e uma deterioração da qualidade de vida da população.

\section{REFERÊNCIAS}

ALBUQUERQUE, F. "Investimento da Caixa em habitação cresceu mais de 50\% em 2010". In: Jornal do Brasil On Line, 11/02/2011. Disponível em $<$ http://www.jb.com.br/economia/noticias/2011/02/11/investimento-da-caixa-em-habitacao-cresceumais-de-50-em-2010>. Acesso em Fev. 2011.

ARANTES, P. F.; FIX, M. "Como o governo Lula pretende resolver o problema da habitação". In: Caros Amigos, 2009. Disponível em: http://carosamigos.terra.com.br. Acesso em Março 2014.

ARRETCHE, Marta. "Intervenção do Estado e setor privado: o modelo brasileiro de política habitacional." Espaço e Debates, n. 31, p. 21-36, 1990.

AYMONINO, Carlo. La vivienda racional - Ponencias de los congresos: CIAM 1929-1930, Gustavo Gilli, 1973. 
AZEVEDO, Sérgio de; ANDRADE, Luis Aureliano Gama de." Habitação e Poder: da Fundação da Casa Popular ao Banco Nacional da Habitação”. Rio de Janeiro: Zahar, 1982.

BENETTI, Pablo. “A experiência modernista.” Habitação Social e cidade: desafios para o ensino de projeto. n.1, p.19-30, 2012

BOLAFFI, G. "Para uma nova politica habitacional e urbana: possibilidades econômicas, alternativas operacionais e limites políticos". In: VALLADARES, Licia do Prado (Org.). Habitação em questão. Rio de Janeiro: Zahar Editores, 1981. p.167-196.

BRASIL. Lei $n^{\circ} 11.888$, de 24 de dezembro de 2008. Lei da Assistência Técnica.

BONDUKI, Nabil. "Origens da Habitação Social no Brasil.” Arquitetura moderna, Lei do Inquilinato e difusão da casa própria. São Paulo: Estação Liberdade: FAPESP, 1998.

BRASIL. Lei $n^{\circ}$ 11.977, de 07 de julho de 2009. Lei do Programa Minha Casa, Minha Vida PMCMV.

CAVALCANTI, Sandra. Depoimento, in FREIRE, Américo, OLIVEIRA, Lucia Lippi. "Capitulos da memória do urbanismo carioca." Rio de janeiro: Ed. Folha Seca, 2002.

FIGUEROLA, V. N. "O Programa Minha Casa, Minha Vida articula planejamento urbano à política habitacional?". In: AU - Arquitetura e Urbanismo, São Paulo, ano 24, n. 182, p. 12-13, Mai. 2009.

FREITAS, Eleusina Lavôr Holanda. "Como qualificar conjuntos habitacionais populares “. Disponível em: http://www.usp.br/fau/depprojeto/labhab/biblioteca/teses/freitas mestrado_comoqualificar.pdf.

Acesso em Junho 2014. Brasília: Caixa Econômica Federal, 2004.

INSTITUTO MORADIA, Projeto Moradia, São Paulo, Julho de 2000.

MARICATO, ERMINIA. Um Panorama da Habitação Popular em Londres, Eua e Brasil. Disponível em: $\quad$ http://video.globo.com/Videos/Player/Noticias/0 „,GIM10046957823UM+PANORAMA+DA+HABITACAO+POPULAR+EM+LONDRES+EUA+E+BRASIL, 00.ht ml. Acesso em Março 2014.

MEDEIROS, Sara Raquel Fernandes Queiroz. "BNH: outras perspectivas". Disponível em: http://www.cchla.ufrn.br/cnpp/pgs/anais/Artigos\%20REVISADOS/BNH,\%20outra\%20pespectiva.pdf . Acesso em Junho 2014.

MORADO NASCIMENTO, Denise; TOSTES, Simone Parrela. "Espaço público e políticas habitacionais lusófonas". In: Congresso Internacional (DA) Habitação no Espaço Lusófono, 1., 2010, Lisboa. Lisboa: ISCTE/IUL, 2010, p.1-23. [CD]

MORADO NASCIMENTO, D., BRAGA, R. C. Q. "Déficit habitacional: um problema a ser resolvido ou um número a ser superado". In: Risco Revista de Pesquisa em Arquitetura e Urbanismo/Programa de Pós-graduação do Departamento de Arquitetura e Urbanismo EESC-USP, São Carlos, n.9, p.98109, $1^{\circ}$ sem. 2009.

NASCIMENTO, Denise. Programa Minha Casa Minha Vida: a (mesma) política habitacional no Brasil (1). Belo Horizonte, 2011. Disponivel em: http://www.vitruvius.com.br/revistas/read/arquitextos/12.133/3936. Acesso : Junho 2014

PALHARES, SERGIO. "Variantes de modificação em habitação popular: Do espaço planejado ao espaço vivido." Belo Horizonte, P.42, 2001. Disponivel em: http://www.mom.arq.ufmg.br/mom/01_dissertacoes/palhares.pdf. Acesso: Junho 2014 
PALHARES, SERGIO. "Variantes de modificação em habitação popular: Do espaço planejado ao espaço vivido." Belo Horizonte, 2001. Disponivel em: http://www.mom.arq.ufmg.br/mom/01 dissertacoes/palhares.pdf. Acesso: Junho 2014.In: GROPIUS, Walter. "Bauhaus - novarquitetura”. São Paulo: Perspectiva, 1972.

ROLNIK, Raquel. Relatora especial para o Direito à Moradia da ONU. Rede de Tecnologia Social, 27/05/2009. Disponível em http://www.rts.org.br/entrevistas/entrevistas-2009/raquel-rolnik/. Acesso em Março 2014.

ROLNIK, Raquel. Como produzir moradia bem localizada com recursos do programa minha casa minha vida?: implementando os instrumentos do Estatuto da Cidade. Brasília: Ministério das Cidades, 2010. p. 20.

TOSTES, Simone. Programa Minha Casa Minha Vida: a (mesma) política habitacional no Brasil (1). Belo Horizonte, 2011. Disponivel em: http://www.vitruvius.com.br/revistas/read/arquitextos/12.133/3936. Acesso : Junho 2014 